\title{
The Value of Using Top-Down and Bottom-Up Approaches for Building Trust and Transparency in Biobanking
}

\author{
E.M. Meslin \\ Indiana University Center for Bioethics, Indiana University School of Medicine, Indianapolis, Ind., USA
}

\section{Key Words \\ Biobanks · Ethics · Governance $\cdot$ Public trust · Transparency}

\begin{abstract}
With the domestic and international proliferation of biobanks and their associated connections to health information databases, scholarly attention has been turning from the ethical issues arising from the construction of biobanks to the ethical issues that emerge in their operation and management. Calls for greater transparency in governance structures, coupled with stern reminders of the value of maintaining public trust, are seen as critical components in the success of these resources. Two different approaches have been adopted for addressing these types of ethical issues: the first is a 'top-down' approach which focuses on developing policy, procedures, regulations and guidelines to aid decision-makers. The second is a 'bottom-up' approach, which begins with those who are most affected by the issues and attempts to inductively develop consensus recommendations and policy. While both approaches have merit, I argue that more work needs to be done on 'bottom-up' strategies if trust and transparency are to be more than mere slogans. Using 2 case examples from Indiana, the paper summarizes data from a set of surveys we recently conducted that address issues arising from biobanks that provide some insight into issues associated with trust and transparency.
\end{abstract}

Copyright $\odot 2010$ S. Karger AG, Basel (c) 2010 S. Karger AG, Basel

Accessible online at: www.karger.com/phg

\section{Introduction}

The domestic and international proliferation of biobanks and their associated connections to health information databases continues to generate considerable scholarly attention focusing on understanding the ethical issues that arise from the construction of biobanks [1-8]. Equally important, however, are those studies that examine the ethical issues that emerge in the operation and management of these resources [9-16]. Good governance of biobanks is a critical component for successfully utilizing these resources by providing the public with an assurance of accountability that enhances their trust in the overall enterprise [11, 14, 17-19].

Elsewhere I have described the strengths and weaknesses of 2 complementary approaches for understanding ethical and policy issues in bioethics, which I have referred to as 'top-down' and 'bottom-up' [20, 21]. 'Topdown' approaches tend to utilize expert input with the aim of developing policy, procedures or guidelines. These policy instruments are intended to be generalizable and therefore universalizable instruments that can apply to many people. Whereas the product of top-down efforts are easily recognized (e.g. a published regulation or guideline), the process of dissemination and the assessment of impact is somewhat less straightforward since it presumes a type of trickle-down phenomenon will occur in which those who are most affected will be the beneficiaries of the wisdom from the various attempts to regulate or guide [20].

\section{KARGER}

Fax +41613061234

-Mail karger@karger.ch

www.karger.com
Eric M. Meslin, PhD

Indiana University Center for Bioethics, Indiana University School of Medicine 410 West 10 th Street, Suite 3100

Indianapolis, IN 46202 (USA)

Tel. +1 317278 4040, Fax +1 317278 4050, E-Mail emeslin@iupui.edu 
A contrasting approach begins from the opposite direction, by focusing one's ethical gaze upon the cases and controversies themselves - with all their inherent messiness and conflict - and then attempt to derive policy and procedure that is more closely linked to real problems. Bottom-up approaches take into account the specific local circumstances of the case itself, often using empirical data, lived experience, personal accounts, and circumstances as the starting point for developing policy solutions [20]. Given the value that both approaches may bring to policy generally, this paper will examine their value for biobanking in particular.

\section{Biobank Governance from the Top Down}

Evidence of the top-down approach in biobanking can be found everywhere, whether in the form of common principles and commitments or a variety of statements, regulations, policies, guidance, declarations or protocols $[15,16,22-27]$. Efforts to update existing policies and regulations to accommodate biobank research have been underway for many years in the domestic U.S. and international environments [9-11, 13, 23-25, 28, 29]. Supplementing these actions have been calls for greater transparency in governance often coupled with stern reminders of the value of maintaining public trust, both of which are seen as critical components in the successful deployment of these resources [11, 13, 14, 17-19].

This emphasis on guideline development is not surprising. The construction and use of biobanks fall squarely within the domain of research involving human subjects, an area of activity in the life sciences that is governed by national and international guidelines, agreements, and other oversight instruments. To take one example with which I am familiar, the National Bioethics Advisory Commission's (NBAC) report on research involving human biological materials [23] contributed to a national discussion in the U.S. and elsewhere principally because it identified some of the key empirical and policy gaps that existed for the oversight of this area of genetics research. Aided by a study prepared by Elisa Eiseman (who later expanded it into other authoritative documents [30,31]), the NBAC provided the first-ever census of the number of biological materials stored in U.S. pathology departments, laboratories and repositories. Although we knew that the estimate of approximately 282 million samples was low since it did not include many proprietary databases or classified military repositories, it is a testament to Eiseman's initial research that com- mentators still quote her original estimate as the definitive reference number for the U.S. and more importantly, use this data to justify the need for policy approaches to biobank governance.

The NBAC also took on some of the key issues that were starting to emerge for genomics researchers for which policy guidance was lacking. The NBAC's recommendation that research using coded samples should be treated as if they were identifiable (and therefore human subjects research warranting institutional review board [IRB] review and approval) was a provocative proposal in 1999: for some it was seen as a necessary brake on unbridled research and by others as an unwarranted limitation on important studies [23]. It is noteworthy that in the years following these recommendations, U.S. regulations moved towards greater clarification about the status of coded samples. For example, the Office for Human Research Protections initially determined in 2004 and later reaffirmed in 2008 [16] that research involving coded samples did not fall within the definition of 'human subjects research' within the Common Rule (the informal name of the Federal Policy for the Protection of Human Subjects) [32] and was therefore not subject to informed consent requirement or ethics review. This clarification also brought greater transparency to a problem that emerged during the NBAC's review, namely that the Food and Drug Administration had a slightly different interpretation of the requirements for informed consent involving banked samples [33] - a situation that caused a certain amount of confusion [34].

One can see how the NBAC's work, supplemented by empirical research on biobanks, aided the development of U.S. policy in this area - a clear example of a top-down approach. Indeed, in the years since the NBAC's initial work there has been no shortage of guidance documents on these topics. A search of the authoritative HumGen database (http://www.humgen.org/int/GB2_p.cfm?mod=1) on October 1, 2009 listed 52 international, 38 regional and 204 national guidance documents on the topic of biobanks alone.

\section{Problems with Top-Down Approaches}

The policy products and developments described above should be regarded as good evidence of the seriousness that governments, funding bodies and regulatory authorities place on the importance of providing clarity on key issues in biobank governance. Indeed, these topdown approaches serve the function of democratizing the governance process by developing standards and procedures for adoption. Of course, like all deductive efforts in 
policy - whether the goal is to define concepts or develop guidelines - top-down efforts work best if the documents provide greater clarity, a common language or a more understandable interpretation of a particular problem. A guideline that clarifies will be more likely to aid decisionmaking than one that does not. Moreover, a guideline that enjoys broad consensus is usually the product of a process that must also satisfy legal, regulatory and political requirements.

Unfortunately, bioethics has its share of examples in which the development of a guideline has obscured rather than clarified the issues. In the U.S. we have observed this phenomenon in the regulation of human subjects research where lack of clarity has produced inconsistent interpretation [34-36]. Similarly, the many revisions of the Declaration of Helsinki and the emergence of the International Conference on Harmonization process have also created a certain amount of confusion with respect to international standards [37]. We should not be surprised that top-down decision-making creates problems of interpretation. This is less a flaw in the process of top-down policy construction than it is of translation. However, the risks of this translation problem are real. A policy for implementing best practices in biobanking, no matter how well developed, will be of minimal use if it fails to reach those to whom it is directed. And even if it does somehow reach these stakeholders, there will always be the risk that the message will go unheard or be misinterpreted as it moves its way through bureaucracy. Until very recently, there was just this sort of confusion in the U.S. with respect to subtly different interpretations of consent requirements for biobanking in the Food and Drug Administration regulations and the Common Rule [34].

\section{Approaching Issues from the Bottom Up}

In contrast with these top-down policy approaches are strategies that start from the other, opposite direction. These 'bottom-up' approaches begin with those who are most affected by the problem and attempt to develop a more inductive strategy to capacity building $[20,21]$. In biobanking 2 general types of bottom-up activity may be discerned. The first type consists of efforts to enhance the capacity of researchers to appreciate the ethical issues that they face in designing and conducting research. This is accomplished through a variety of methods including training and education where the ideal is that an ethically aware investigator is more likely to design and conduct research that attends to relevant ethical issues. The second type focuses on enhancing local capacity to conduct scientific and ethics review of research protocols. Research ethics capacity building from the bottom-up looks very different from top-down approaches. The principal difference is the relevance of local circumstances: capacity building from the bottom-up often begins with a commitment to meet individual and community needs first and national or global interests second [20]. These approaches establish precedents and procedures that work locally and may, if generalized, form the basis of best practices for others. Perhaps the best way of summarizing the difference between top-down and bottomup approaches plays a little on language: top-down approaches place heavy emphasis on the procedure of establishing policy, whereas bottom-up approaches place their emphasis on the policy of establishing procedures.

Developing and promulgating guidelines for the collection, storage, and use of human biological materials is a valuable and necessary activity. But so too is coming to agreement about how to discuss and address the particular instances of cases. A simple example may be illustrative: in the U.S. some academic medical centers building or expanding their own biobanks have observed with interest the development of the Vanderbilt University biobank program [24]. If these same universities were to adopt Vanderbilt's program (in whole or in part) we might describe this as a bottom-up approach. In contrast, institutions might choose to rely on the best practices criteria for high quality biobanks such as those proposed by Eiseman et al. [31] or by authoritative international organizations such as the OECD [15]; in so doing they would be adopting a top-down approach.

Bottom-up approaches are not without their own set of challenges; like any case-based approach there are risks of generalizing from a limited and particular set of facts to a policy framework intended to cover a comprehensive set of cases. What is gained in depth from the granular detail achieved by understanding the local context may be lost when a policy based on that single case is widely disseminated. In what follows, I will show how both approaches (top-down and bottom-up) can be used to assure trust and transparency in biobanking.

\section{Experience from Biobank Governance in Indiana}

In the spring of 2001 I received a phone call from a senior researcher at Indiana University who was calling to seek my help with one of the university's IRBs which he thought was taking an unnecessarily restrictive view 
about approving the construction of a biobank. He was frustrated because, he told me, the IRB had informed him that U.S. federal regulations prohibited the approval of a consent form that would permit patients to consent to donating samples to a biobank that would be retained and used for prospective, unspecified future research use. The IRB also worried (he lamented) about the consent form's failure to describe in detail how some of the likely end users of these valuable samples - the pharmaceutical, biotechnology, and device companies in Indiana and elsewhere - would be getting access to them. Although he did not specify which regulations were being relied upon, he was almost certainly referring to both the Common Rule [32] and the relevant regulations of the U.S. Food and Drug Administration [38]. The telephone request was treated as a research ethics consultation for our Center. As I will show below, what was initially seen as a straightforward consult to provide interpretations of relevant federal regulations soon became an exercise in bottom-up policy analysis.

\section{Using the Top-Down Approach}

After a number of meetings with the investigator, we decided to prepare a briefing memo that could be used to inform the IRB about the 'state of the debate' in biobanking at that time, and further to propose a possible policy solution that the IRB could adopt for future protocol review. We first conducted a policy assessment to determine whether the IRB's intuition that they were somehow limited to certain types of conclusions (or prohibited from approving certain types of consent forms) was an accurate interpretation of U.S. federal regulations. We determined that while there was a certain amount of ambiguity in regulations for the protection of human subjects, sufficient clarity was provided by existing guidance documents to permit considerable local discretion [34, $40,41]$. In other words, U.S. regulations provided IRBs with the authority they needed to make determinations about whether consent forms could be constructed to permit broadly permissive informed consent and about disclosures regarding the possible commercialization of the banks themselves. While a briefing memo containing our analysis of applicable regulations might have been sufficient, our team did not think it would make a compelling argument to the IRB. We believed that their initial reluctance to approve biobank studies involving broad consent may have reflected an understandable concern about the possible precedent that might be established had their approval been based solely on an interpretation of the regulations and not on any empirical data regard- ing public willingness to participate in biobanks. Given the history of well-publicized cases of research ethics abuses in the U.S. coupled with the increased attention paid to ethical oversight exhibited by the U.S. Congress, this reluctance was understandable. A top-down approach did not alone provide a thorough-going understanding of what was at stake. What was needed was data from the bottom-up.

\section{Using the Bottom-Up Approach}

Our second strategy was to gather and summarize available data on the topic of public willingness to participate in biobanks which would allow us to better understand what was at stake by those most affected by biobank research. We were already aware of the growing empirical literature on this topic, especially regarding the public's willingness to donate tissue or other biological material to science in general and to biobanks in particular. In a comprehensive, but not exhaustive review of this empirical literature that we conducted on PubMed in early 2009 we found no fewer than 60 studies, with at least 20 surveys published between February 2008 and January 2009. Space does not permit a thorough review of these papers, but at the risk of simplifying a very robust set of studies undertaken on different groups of people, in different countries, under different conditions, being asked different questions, it would appear that in recent years there has been a gradual increase in the public's expression of willingness to participate in biobanks between 1998 (when the NBAC first undertook its study) and 2009. Willingness to participate is, however, a squishy notion to say the least since the general trend may be qualified by very relevant facts and contexts.

\section{More Data from Indiana}

Our assessment of the broad empirical literature on public willingness provided more evidence to support our top-down policy analysis. But still we felt we needed to drill down even deeper - to learn more about specific attitudes in Indiana. Our thinking was that since IRBs are expected to understand the local context when evaluating protocols, it might be valuable to collect local data. We also undertook several studies as part of an ongoing project to identify and analyze ethical issues in predictive health research. Three of these surveys are briefly described.

In 2006-2007 we surveyed cancer patients who contributed leftover tissue to the Indiana University Cancer Center Tissue Bank [42] and found that a clear majority of subjects would permit unlimited future research on 
stored human biological materials without re-contact and re-consent; and, further, that a significant minority appears to desire ongoing control over future research uses of their tissue.

In 2007-2008, when we surveyed women in community health clinics to estimate their willingness to donate specimens for DNA analysis by needle stick as compared with collection of saliva, the majority of the 279 women surveyed would give DNA specimens by needle stick $(68.3 \%)$, but more would be willing to donate saliva (75.7\%) [5].

In both of these surveys, we learned that support for biobanking was modulated by certain factors. For example, in our study of cancer patients about two thirds $(62.6 \%)$ of respondents agreed or strongly agreed that it was 'all right' for researchers to use their donated tissue to develop a new tool or treatment for profit though support for 'for profit' biobanking varied somewhat with this population depending on age, education and other demographic factors [42]. In our study involving women in the community health clinic, we found a number of reasons why they indicated an unwillingness to participate, including worries about the use of the specimens, violation of privacy, the potential for future discrimination, and the fear surrounding unfavorable results [5].

We also undertook a more comprehensive telephone survey of more than 1,000 Indiana adults in 2007-2008. One of the aims was to determine public confidence in medical and genetic research [43]. Two general confidence questions were asked of respondents in this survey: (a) 'On a scale of 1 to 10 , where 10 is "extremely confident" and 1 is "no confidence at all", how confident are you that medical research in the U.S. is being conducted with the best interests of people like you in mind?' (b) 'How confident are you that genetic research in the U.S. is being conducted with the best interests of people like you in mind?' Responses were grouped into ratings of low (rating of 1-4), moderate (rating of 5-7), or high (rating of 8-10) confidence. Figure 1 summarizes these responses. Slightly more than half stated moderate confidence in medical research being in the public's best interest. More than one third (35.5\%) expressed high confidence, and approximately $14 \%$ of the public expressed low confidence. In contrast, nearly even proportions expressed high (43.8\%) and moderate (45.2\%) confidence in genetic research; $11 \%$ stated low confidence in genetic research being in the public's best interest.

When asked about genetic research, people who stated a confidence level lower than 8 were then asked, 'What is the one main reason you are not "extremely confident" in

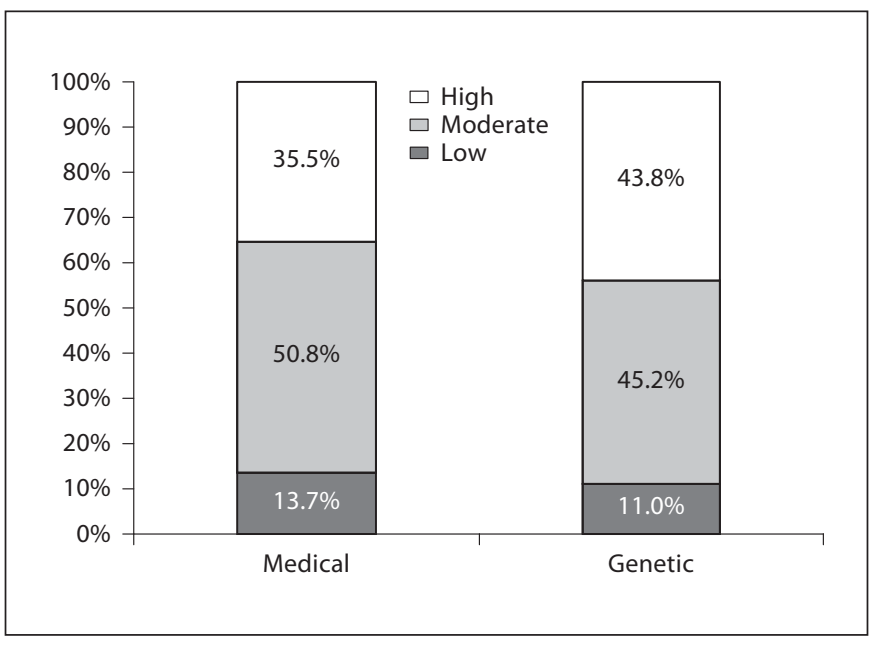

Fig. 1. Public confidence in medical and genetic research.

genetic research?' The verbatim responses which are found in the full report [43] were clustered into 3 categories: (a) suspicion that genetic research is all about profit; (b) genetic research is not showing adequate progress; (c) belief that genetic research is morally wrong. Examples of responses relating to 'suspicion that genetic research is all about profit' included the following:

'Big businesses tailor the research to fit their needs and what's going to make them the most money.'

'I think that all research is done ultimately for information but ends up being for the companies' profits.'

Examples of responses relating to 'not showing adequate progress' included:

'Well, in my own family, there's a situation where I know it's hereditary and I just don't think they've done enough to cure it or control it better'.

'They've been doing it for a long time and cures should have been found for MS and other diseases.'

'Because there's so many diseases that man has no cure for such as cancer, it's been around for many years and yet man can't cure cancer.'

Examples of responses relating to 'genetic research is morally wrong' included:

'I have, just when it comes to genetics, when you go into people's DNA, you've got to worry about people copying things they shouldn't copy. You know, cloning, things like that.'

'I worry about the consequences.'

'End use of this information, how it will be used after researchers are done with the data. I am not concerned about how the initial researcher there used the data.' 
'I feel like it has a tendency to be used in the wrong way and for deceptive purposes.'

Data like these are informative but not dispositive. The fact that respondents identified commercial issues as among those that influenced their level of confidence and trust tells us something about the nature of their concern, but not a lot. For example, until recently, economic factors associated with the way in which biobanks are organized received relatively little attention $[9,15,39,44]$. Indeed, when the Winikoffs first proposed that biobanks be organized as 'charitable trusts' suggesting that economic and political factors must be accommodated alongside ethical, legal and social factors, there were few opponents to their proposal [45]. Efforts to unpack this issue have proven difficult.

We also surmised that there are other objections to the economics of biobanking that warrant further study from the bottom-up. It is likely that some people object to any type of commerce in tissues because of the moral association with commodification of the body as property. Others may object because they are skeptical of the motives of certain sponsors - private sector companies, federal funding agencies and philanthropies each support biobanks. Still others might have an enduring skepticism about the growing entrepreneurial nature of medicine [46]. These objections differ from the argument that any plan seeking to profit from biobanking that fails to directly compensate donors unfairly discriminates against the individual that was the source of the tissue. Getting clear on these objections from the bottom-up will help determine whether they are objections that might derail genomic research and any of the potential benefits that may flow therefrom, or whether they are simply points that need to be taken into account.

Addressing even a few of these issues might serve as incentives for more genomic research. My colleague, Barbara Evans and I tried to explain the incentive issue with an analogy to refrigerator warranties. We hypothesized the potential of personalized medicine by thinking about a world in which predictive testing and drug targeting were so precise that patients could almost be assured with a guarantee that the drug they were prescribed following a simple blood test would work for them. That world exists now for refrigerators - guarantees in the form of warranties are evidence of the manufacturer's confidence in their product. Our current model of prescribing is known to harm up to $7 \%$ of patients. We therefore somewhat audaciously analogized that if new refrigerators hurt $7 \%$ of customers and failed to work for another one third of them, customers would expect refunds' [44]. If the future of predictive medicine is leading towards far greater capacity to accurately diagnose medical problems and to more accurately prescribe medicines that have an extremely high likelihood of working (and of not harming) it is not much of a leap to imagine that patient expectations of 'guarantees' will increase as doctors come closer to making claims that a drug will work for them as advertised. Moreover, it is also not much of a stretch to imagine that marketing of biopharmaceuticals will include stronger claims about the superiority of their product.

For a country like the U.S., the upside is very powerful: if the estimates are accurate that only $\sim 60 \%$ of the prescriptions written produced desired benefits and that overall prescription drug spending (in 2002) was USD 162.4 billion, then simple math tells us that as much as about USD 65 billion (40\% of USD 162.4 billion) was spent on prescription drugs that either did not help patients or actually harmed them [44]. At a time when the political environment is receptive to significant health reform, this might be a further way to increase coverage and control the costs of technology [47].

\section{Conclusion}

It would seem we are at a crossroads of sorts. The first road leads us further towards the development and refinement of top-down guidance documents. Indeed, there appears to be an evolving recognition of the importance of biobanking and a growing set of guidance documents that offer roadmaps for ethical research that protect human subjects. The second road focuses our attention on better understanding the impact of biobank governance. There is the perception (evidenced through surveys of public opinion) that there is support for biobanking, but it is tempered by concerns about economic benefits and commercial opportunities. There are risks of taking either road alone. But taken together, these 2 roads suggest an evolution in thinking is geared towards a more permissive approach to biobanking.

When we portrayed the state-of-the-art in biobanking governance only from the top-down perspective, we got little traction in Indiana. When we portrayed the regulatory analysis along with the bottom-up data from our surveys and others, we got substantially more (though not complete) traction. In this regard, our experience was not unlike many other institutions in the U.S. and elsewhere who are trying to steer carefully between the research opportunities represented in their existing bio- 
banks (not to mention the biobanks they intend to build) and the regulatory ambiguity that exists in domestic and international governance documents. This ambiguity, coupled with a more explicit recognition of the scientific and financial value of biobanks, may mean that more innovative approaches to building trust and transparency are required. The next steps in governance ought to take into account the contributions of both top-down and bottom-up approaches.

\section{Acknowledgement}

An earlier version of this paper entitled 'Transparency, Trust and Translation in Predictive Health Research: Is Commercialization the Problem?' was presented at the 'Genes for Health' Conference, Fremantle, Australia, May 5, 2009. Thanks to 2 anonymous reviewers for their helpful comments on the original submission. Support for this paper was provided in part by the following sources: UL1RR025761-01, NCRR/National Institutes of Health; Richard M. Fairbanks Foundation, Indianapolis. E.M. Meslin is a consultant to Eli Lilly \& Company.

\section{References}

1 Goldman RE, Kingdon C, Wasser J, Clark MA, Goldberg R, Papandonatos GD, Hawrot E, Koren G: Rhode Islanders' attitudes towards the development of a statewide genetic biobank. Per Med 2008;5:339-359.

-2 Axler RE, Irvine R, Lipworth W, Morrell B, Kerridge IH: Why might people donate tissue for cancer research? Insights from organ/ tissue/blood donation and clinical research. Pathobiology 2008;75:323-329.

-3 Bernhardt BA, Tambor ES, Fraser G, Wissow LS, Geller G: Parents' and children's attitudes toward the enrollment of minors in genetic susceptibility research: implications for informed consent. Am J Med Genet A 2003;116A:315-323.

4 Bates BR, Lynch JA, Bevan JL, Condit CM: Warranted concerns, warranted outlooks: a focus group study of public understandings of genetic research. Soc Sci Med 2005;60: 331-344.

5 Haas DM, Renbarger JL, Meslin EM, Drabiak K, Flockhart D: Patient attitudes toward genotyping in an urban women's health clinic. Obstet Gynecol 2008;112:1023-1028.

-6 Helgesson G, Swartling U: Views on data use, confidentiality and consent in a predictive screening involving children. J Med Ethics 2008;34:206-209.

7 Murphy J, Scott J, Kaufman D, Geller G, Leroy L, Hudson K: Public perspectives on informed consent for biobanking. Am J Public Health 2009;99:2128-2134.

8 Leiman DA, Lorenzi NM, Wyatt JC, Doney AS, Rosenbloom ST: US and Scottish health professionals' attitudes toward DNA biobanking. J Am Med Inform Assoc 2008; 15: 357-362.

9 Kaye J, Stranger M (eds): Principles and Practice in Biobank Governance. Surrey, Ashgate, 2010.

10 Caulfield T, Kaye J: Broad consent in biobanking: reflections on seemingly insurmountable dilemmas. Med Law Int 2009; 10: 85-100.
11 Chalmers D: International co-operation between biobanks: the case for harmonisation of guidelines and governance; in Stranger M (ed): Human Biotechnology \& Public Trust: Trends, Perceptions and Regulation. Hobart, Centre for Law and Genetics, 2007, pp 237246.

12 Caulfield T, Brown R, Meslin EM: Challenging a well established consent norm? One time consent for biobank research. J Int Biotechnol Laws 2007;4:69-74.

13 Otlowski M: Key themes in the policy debate on human genetic research and genetic databanks: an evaluation. J Int Biotechnol Laws 2008;5:143-152.

14 Hansson MG: Building on relationships of trust in biobank research. J Med Ethics 2005; 31:415-418.

15 Organisation for Economic Co-operation and Development: Guidelines on human biobanks and genetic research databases. Paris, OECD, 2009.

16 Office for Human Research Protections (OHRP), Department of Health and $\mathrm{Hu}-$ man Services: Guidance on research involving coded private information or biological specimens. 2004. Available at http://www. hhs.gov/ohrp/humansubjects/guidance/ cdebiol04.htm.

17 Caulfield T: Biobanks and blanket consent: the proper place of the public good and public perception rationales. Kings Law J 2007; 18:209-226.

18 Campbell AV: The ethical challenges of genetic databases: safeguarding altruism and trust. Kings Law J 2007;18:227-246.

19 Chadwick R, Berg K: Solidarity and equity: new ethical frameworks for genetic databases. Nat Rev Genet 2001;2:318-321.

20 Meslin EM: Achieving global justice in health through global research ethics: supplementing Macklin's 'top-down' approach with one from the 'ground up'; in Green RM, Donovan A, Jauss SA (eds): Global Bioethics: Issues of Conscience for the Twenty-First Century. New York, University Press, 2009, pp 163-177.
21 Sidle JE, Were E, Wools-Kaloustian K, Chuani C, Salmon K, Tierney WM, Meslin EM: A needs assessment to build international research ethics capacity. J Empir Res Hum Res Ethics 2006;1:23-38.

22 Caulfield T, McGuire AL, Cho M, Buchanan JA, Burgess MM, Danilczyk U, Diaz CM, Fryer-Edwards K, Green SK, Hodosh MA, Juengst ET, Kaye J, Kedes L, Knoppers BM, Lemmens T, Meslin EM, Murphy J, Nussbaum RL, Otlowski M, Pullman D, Ray PN, Sugarman J, Timmons M: Research ethics recommendations for whole-genome research: consensus statement. PLoS Biol 2008; 6:e73.

23 National Bioethics Advisory Commission: Research Involving Human Biological Materials: Ethical Issues and Policy Guidance, Volume I: Report and Recommendations of the National Bioethics Advisory Commission. Bethesda, MD, National Bioethics Advisory Commission, 1999. Available at http:// bioethics.georgetown.edu/nbac/pubs.html.

24 Roden DM, Pulley JM, Basford M, Bernard GM, Clayton EW, Balser JR, Masys DR: Development of a large-scale deidentified DNA biobank to enable personalized medicine. Clin Pharmacol Ther 2008;84:362-369.

25 UNESCO: Report of the International Bioethics Committee of UNESCO (IBC): On Consent. Paris, UNESCO, 2008.

26 Council of Europe: Recommendation (2006) (4) of the Committee of Ministers to Member States on Research on Biological Materials of Human Origin, 2006. Available at https:// wcd.coe.int/ViewDoc.jsp?id=977859\&Back ColorInternet $=9999 \mathrm{CC} \&$ BackColorIntranet $=$ FFBB55 \&BackColorLogged $=$ FFAC75, accessed 06/07.

27 World Health Organization: Genetic databases: assessing the benefits and impact on human and patient rights, Geneva, WHO, 2003.

28 Office for Protection from Research Risks: Issues to consider in the research use of stored data or tissues, 1997. Available at http://www.hhs.gov/ohrp/humansubjects/ guidance/reposit.htm. 
29 National Institutes of Health, Secretary's Advisory Committee on Genetics, Health and Society: U.S. System of Oversight of Genetic Testing: a response to the charge of the Secretary of Health and Human Services, 2008.

30 Eiseman E, Haga SB: Handbook of human tissue sources: A national resource of human tissue samples. Santa Monica, Rand Corporation, 1999.

31 Eiseman E, Bloom G, Brower J, Clancy N, Olmsted SS: Case studies of existing human tissue repositories: 'best practices' for a biospecimen resource for the genomic and proteomic era. Santa Monica, Rand Corporation, 2003.

32 Office for Human Research Protections: Federal Policy for the Protection of Human Subjects (The Common Rule). 45 CFR 46. Subpart A. Available at http://www.hhs.gov/ ohrp/policy/common.html.

33 Food and Drug Administration, Center for Devices and Radiological Health (CDRH), Office of Compliance, Division of Bioresearch Monitoring (BIMO): Regulating in vitro diagnostic device (IVD) studies, 1999. Available at http://www.fda.gov/cdrh/comp/ ivdreg.html.
34 Evans BJ, Meslin EM: Encouraging translational research through harmonization of FDA and Common Rule informed consent requirements for research with banked specimens. J Leg Med 2006;27:119-166.

35 Evans BJ, Flockhart DA: The unfinished business of U.S. drug safety regulation. Food Drug Law J 2006;61:45-63.

36 Evans BJ: Inconsistent regulatory protection under the U.S. Common Rule. Camb Q Healthc Ethics 2004;13:366-379.

37 Kimmelman J, Weijer C, Meslin EM: Helsinki discords: FDA, ethics, and international drug trials. Lancet 2009;373:13-14.

38 Food and Drug Administration: Protection of Human Subjects. 21 C.F.R. Parts 50, 56, 2005. Available at http://www.accessdata. fda.gov/scripts/cdrh/cfdocs/cfcfr/ CFRSearch.cfm?CFRPart $=50$.

39 Evans BJ: Finding a liability-free space in which personalized medicine can bloom. Clin Pharmacol Ther 2007;82:461-465.

40 Drabiak-Syed K: State codification of federal regulatory ambiguities in biobanking and genetic research. J Leg Med 2009;30:299327.

41 Wolf LE, Lo B: Untapped potential: IRB guidance for the ethical research use of stored biological materials. IRB 2004;26:1-8.
42 Helft PR, Champion VL, Eckles R, Johnson CS, Meslin EM: Cancer patients' attitudes toward future research uses of stored human biological materials. J Empir Res Hum Res Ethics 2007;2:15-22.

43 Survey Research Center at IUPUI: Public attitudes regarding genetic research: survey methods and findings. Indiana University-Purdue University, Indianapolis, 2009. Available at https://scholarworks.iupui.edu/ handle/1805/1959.

44 Evans BJ, Flockhart DA, Meslin EM: Creating incentives for genomic research to improve targeting of therapies. Nat Med 2004; 10:1289-1291.

45 Winickoff DE, Winickoff RN: The charitable trust as a model for genomic biobanks. N Engl J Med 2003;349:1180-1184.

46 Fife RS, Keener P, Meslin EM, Randall M, Schiffmiller RL: Faculty ownership of medical facilities: inappropriate conflict or an opportunity that benefits physicians and patients? Acad Med 2004;79:1051-1055.

47 Callahan D: Taming the Beloved Beast: How Medical Technology Costs Are Destroying Our Health Care System. Princeton, N.J., Princeton University Press, 2009. 